\title{
LAS ESCULTURAS BARROCAS ITALIANAS DE LOS JARDINES DE LA EMBAJADA DE ESPAÑA EN LISBOA
}

\author{
POR \\ TERESA LEONOR M. VALE \\ Profesora auxiliar de la Universidad Lusófona de Humanidades y Tecnologías de Lisboa
}

En los jardines del palacio del sigo XVII, propiedad del Estado Español, que alberga su embajada en Lisboa, es posible apreciar un notable conjunto - aunque no homogéneo, ya que es cronológicamente diversificado (siglos XVII y XVIII) y también con distintas proveniencias (Génova y probablemente Roma) - de obras de escultura barroca italiana.

D. Luís Lobo de la Silveira (1640-1706) y D. Rodrigo da Silveira Silva e Teles (1663-1735), respectivamente $2^{\circ}$ y $3^{\circ}$ condes de Sarzedas, propietarios del palacio durante el siglo XVII y primeras décadas del XVIII, habrán sido los responsables del encargo de estas piezas, de las cuales hoy sobreviven las siguientes: tres fuentes localizadas en el jardín superior, una estatua de Hércules (perteneciente a una antigua fuente) y además cuatro figuras (de carácter mitológico o alegórico) en el patio. Estas cuatro últimas estatuas en particular son de especial importancia, una vez que enriquecen el panorama de la escultura italiana importada por agentes portugueses en el barroco y prueban la existencia en Portugal (y concretamente en los jardines del palacio de la embajada de España) de obras del escultor genovés Bernardo Schiaffino (1678-1725), un hecho hasta aquí desconocido por la historiografía del arte portugués y extranjero.

Palabras clave: Escultura barroca italiana. Escultura genovesa. Embajada de España. Palhavã. Sarzedas

In the gardens of the seventeenth century palace, property of the kingdom of Spain, in which is the Spanish embassy in Lisbon, we can observe a group - although not an homogeneous one, for the different dates and geographical origins (Genoa and eventually Rome) — of Italian baroque sculpture.

D. Luís Lobo da Silveira (1640-1706) and D. Rodrigo da Silveira Silva e Teles (1663-1735), second and third counts of Sarzedas, owners of the palace in the $17^{\text {th }}$ century and first decades of $18^{\text {th }}$ century, were almost certainly the commissioners of this works, that today still remain in the property: three fountains (in the upper garden), a statue of Hercules (that belonged to another ancient fountain) and four (allegorical or mythological) statues in the yard. These last four statues in particular, assume a special importance because they enrich the panorama of Italian sculpture imported to Portugal in the baroque period and they prove the existence of works by the Genoese sculptor Bernardo Schiaffino (1678-1725) in Portugal, fact that remained unknown until now.

Key words: Italian baroque sculpture. Genoese sculpture. Spain Embassy. Palhavã. Sarzedas 
El fenómeno de la importación de obras de escultura italiana en el siglo XVII en Portugal: contexto político-cultural, perfil del agente que hace el encargo

En el dominio de la importación de obras de arte italiana para Portugal durante el siglo XVII — temática cuyo estudio nos viene ocupando en los últimos años 1 — podemos afirmar haber reconocido y podido identificar esencialmente tres grupos de agentes importadores:

1. La comunidad italiana residente en Lisboa, económica, social y culturalmente de la mayor relevancia en la capital y

- conocedora del elevado nivel de la producción artística italiana;

- conocedora de la oferta de arte italiana;

- deseosa de rellenar su iglesia nacional, de Nuestra Señora del Loreto, con piezas representativas de aquello que se creaba en Italia;

- poseedora de los recursos económicos para proceder a la adquisición de obras de arte;

- poseedora de los contactos necesarios para consumar y controlar las encomiendas;

- poseedora de una red de transportes (regulares) entre Portugal e Italia, sobre todo entre Lisboa y Génova - ciudad de origen de muchos de los elementos de la comunidad italiana de Lisboa y, por tal motivo, también de muchas de las obras de arte que llegaban para la iglesia del Loreto-

2. Portugueses que contactaron directamente con el arte italiano.

Portugueses que, por distintas razones, viajaron hasta Italia y apreciaron el arte del seicento, y entre los cuales se destacan los diplomáticos y los eclesiásticos. Habiendo regresado a Portugal, evidenciaron hasta que punto la creación artística los había marcado, trayendo consigo algunas piezas. A partir de esta situación se constituyen dos ejemplos relevantes, principalmente D. Luís de Sousa (1637-1690), obispo de Lamego y arzobispo de Braga, embajador de Portugal en Roma de 1675 a 1682 - comprador de un gran número de obras para su propiedad o para la de terceros- y D. Fr. Manuel Pereira (1625-1688), dominico empeñado en la ciudad pontificia en funciones en el seno de su orden y que trajo para Portugal el conjunto de estatuaria barroca que se observa en la capilla de S. Gonçalo de Amarante del antiguo convento de S. Domingos de Benfica, en Lisboa.

3. Elementos de la aristocracia o del clero, cuyo gusto fue educado por la cultura erudita y marcado por la moda europea o que establecieron de forma concreta aunque indirecta un contacto con el arte y la cultura italianas.

No es tarea fácil reconocer aristócratas portugueses adecuados a este perfil en el contexto de la nobleza nacional del siglo XVII, en transición de un panorama de nobleza de solar (caracterizada por una gran ruralidad) hacia un panorama de nobleza de corte, en el seguimiento de la

\footnotetext{
${ }^{1}$ A ella he dedicado mis disertaciones de Maestría y de Doctorado en Historia del Arte: Teresa Leonor M. Vale, A Capela de S. Gonçalo de Amarante na Igreja do Antigo Convento de S. Domingos de Benfica. Um Exemplo de Importação de Escultura Italiana no Século XVII, (Tesis de Maestría en Historia del Arte presentada en la Facultad de Letras de la Universidad de Lisboa), Lisboa, 1994 (texto fotocopiado) y Teresa Lenor M. Vale, A Importação de Escultura Italiana no Contexto das relações Artístico-Culturais entre Portugal e Itália no Século XVII, (Tesis de Doctorado en Historia del Arte presentada en la Facultad de Letras de la Universidad de Oporto), Oporto, 1994 (texto fotocopiado) publicada como Escultura Italiana em Portugal no século XVII, Lisboa, Caleidoscópio, 2004.
} 
Restauración. Efectivamente, uno de los aspectos que caracterizan la estructura sociocultural del Portugal post-Restauración es ciertamente una apertura al exterior, que se constituye como elemento enriquecedor pero igualmente responsable por una escisión (crecientemente perceptible) entre "indígenas" y "extranjerizados", en la expresión de José Sebastião Silva Dias². Pero es esta misma Restauración que arrastra a la carrera militar activa a un número significativo de aristócratas, de este modo alejados de la posibilidad de una más elaborada formación cultural y de un contacto - a través de la realización de viajes - con Europa en general y con Italia en particular.

Es por consiguiente bastante reducido el número de elementos de la aristocracia o del clero cuyo gusto fue educado por la cultura erudita o por la moda en el siglo XVII portugués y que hayan evidenciado cualquier sensibilidad o predisposición para la importación de arte italiano, el cual, de verificarse, quedaría muy probablemente que se debió sobre todo a un contacto indirecto con Italia, o sea, a un contacto con portugueses que, habiendo permanecido en Italia (y especialmente en Roma), fueron marcados por la producción cultural y artística italiana. Es en este reducido grupo de individuos en el que conseguimos reconocer figuras como la del primer marqués de Nisa, D. Vasco Luís da Gama (1612-1676) — que importa libros y otros objetos de arte y cultura a través de D. Vicente Nogueira (n. 1585 y residente en Roma en las décadas de 40 y 50) y de otros portugueses establecidos en la ciudad pontificia, como adelante tendremos oportunidad de constatar- y, sobre todo, D. Luís de Meneses, tercer conde de Ericeira (1632-1690), que encomienda a través del embajador de Portugal en Roma, D. Luís de Sousa, una fuente para su jardín realizada por el más célebre escultor del barroco romano, Gianlorenzo Bernini (1598-1680).

Es precisamente en esta última categoría de agente importador que se integran los condes de Sarzedas, responsables de la presencia de las obras de escultura barroca italiana que pueblan y animan los jardines del palacio de la embajada de España en Lisboa.

Estado de la cuestión: las distintas referencias a las fuentes italianas del palacio de Palhavã

Aunque no sean tan famosas como la fuente berniniana de la residencia de la Anunciada de los condes de la Ericeira, de que la historiografía del arte portugués se ha ocupado abundantemente, las fuentes italianas del palacio de Palhavã merecieron igualmente distintas menciones de los autores a lo largo del tiempo. Tal atención se debió tal vez precisamente a su origen italiano, una vez que tal fue, durante siglos, sinónimo de elevada calidad artística.

La primera referencia que nos ha sido posible encontrar remite al año de 1712 y pertenece al Pe. António Carvalho da Costa que, en su Corografia Portuguesa, señala en la propiedad entonces de los condes de Sarzedas la existencia de “(...) tres jardins, el mayor cõ tres fuentes de pedra de excellente fabrico, que vierão de Italia com hum Hercules de pedra fina [de] marmore, lançando agua por muytas partes de seu corpo (...)."3.

Aproximadamente cincuenta años más tarde (1760), el párroco de la feligresía de S. Sebastião da Pedreira, en su memorando destinado al marqués de Pombal en la secuencia del terremoto de

\footnotetext{
2 Cf. José Sebastião da Silva Dias, Portugal e a Cultura Europeia (Sécs. XVI a XVIII), (separata de Biblos, Tomo XXVIII), Coimbra, Coimbra Editora, 1953, p. 99.

${ }^{3}$ Pe. António Carvalho de la Costa, Corografia Portugueza y Descripçam Topografica del Famoso Reyno de Portugal, Lisboa, Officina Real Deslandiana, 1712, p. 340.
} 


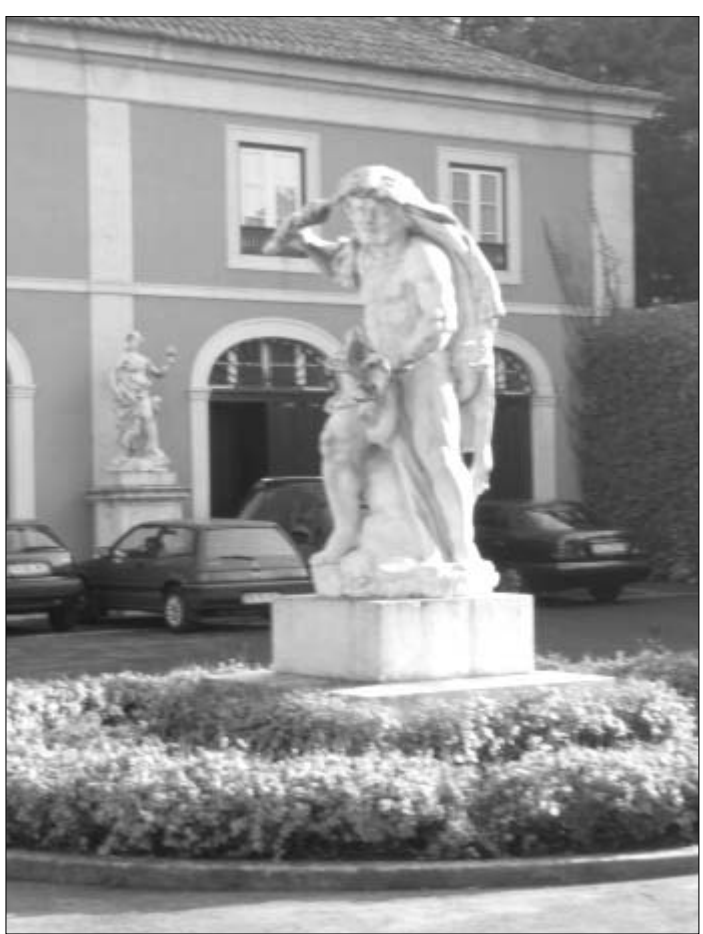

Fig. 1. Estatua de Hércules.

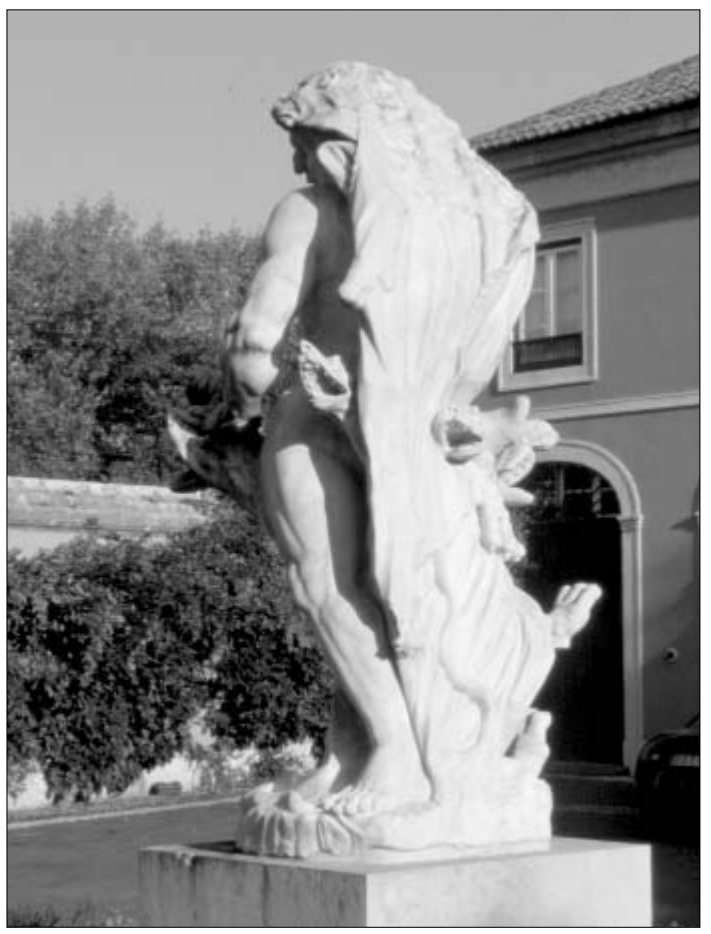

Fig. 3. Estatua de Hércules - detalle (posterior).

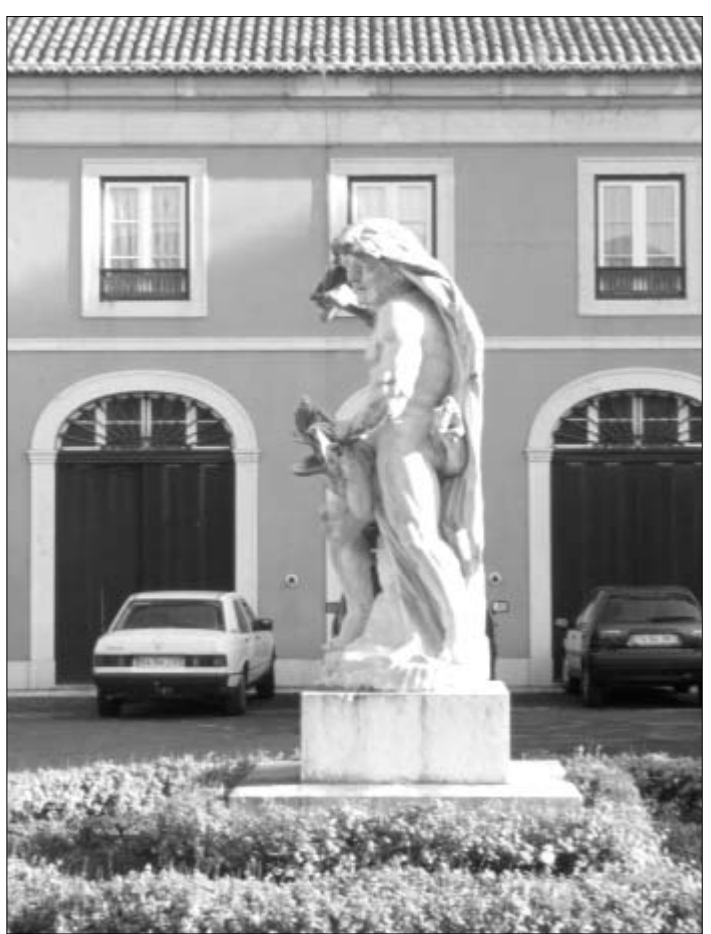

Fig. 2. Estatua de Hércules.

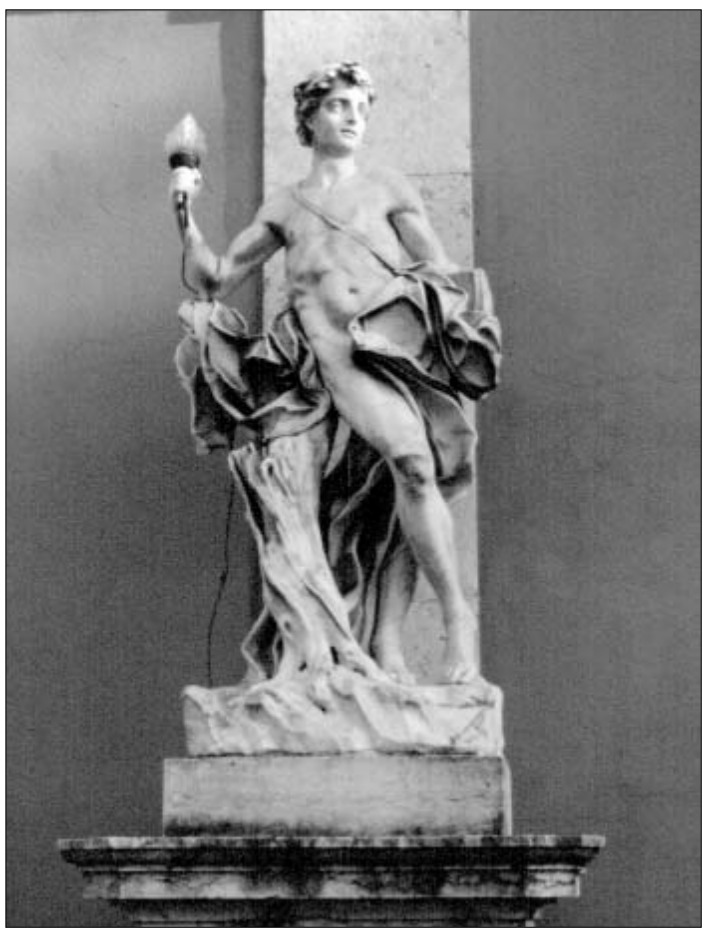

Fig. 4. Estatua genovesa.

AEA, LXXIX, 314, ABRIL-JUNIO, 123-138, 2006, ISSN: 0004-0428 
1755, reconoce en la finca de Palhavã los mismos tres jardines “(...) con fuentes de agoa, com varias figuras de jaspe feitas em Italia (...)."

Los autores del siglo XVIII — tal vez por la proximidad cronológica del encargo y por la fama alcanzada por las obras - fijaron naturalmente el origen italiano de las fuentes del palacio de Palhavã, que la historiografía de la centuria siguiente acepta, llegando incluso Pinho Leal (1875), ante la decadencia de la propiedad, a afirmar lo siguiente: "Desde então [lutas liberais] progrediu a devastação; até que, seus bosques, pomares e jardins foram substituídos por cearas de trigo, por entre as quaes ainda se conservam algumas de suas estatuas gigantescas feitas em Italia, parte d'ellas do celebre esculptor Bernini." 5.

Data de 1923 el primer estudio monográfico dedicado al palacio de Palhavã, cuyo autor, Santos Farinha, aunque sin ningun fundamento documental u otro, afirma claramente el origen italiano e incluso la atribución a Gianlorenzo Bernini de las esculturas de los jardines de la antigua propiedad de los Sarzedas: “(...) o $\left[2^{\circ}\right]$ Conde de Sarzedas edificava o seu Palacio em Palhavan, imprimindo-lhe o cunho de manifesta sumptuosidade, encommendando ao famoso esculptor Bernini artisticas estatuas que decorassem a moradia e ornassem os jardins (...)."6.

Los textos posteriores a la monografía de Santos Farinha se limitan a repetir la proveniencia italiana de las esculturas de los jardines de Palhavã, insistiendo en su atribución a Bernini?

Las obras más recientes se limitan igualmente a subrayar el carácter importado de las fuentes ${ }^{8}$.

Identificación de los responsables de los encargos: el $2^{\circ}$ y $3^{\circ}$ condes de Sarzedas

La propiedad de Palhavã, cuyo origen se remonta al inicio del siglo XVI —siendo entonces compuesta por unas casas nobles edificadas por su propietario, Gomes Lourenço de Palhavã, de la familia Carvalhosas Palhavã (con solar en Carvalhosa, comarca de Guimarães)—, pasa a ser propiedad de los condes de Sarzedas en 1660, fecha en que es vendida por Jorge Gomes Lourenço de Palhavã (bisnieto del ya mencionado Gomes Lourenço de Palhavã ) al $2^{\circ}$ conde 9 .

La finca de Palhavã pasa por consiguiente, en la década de los sesenta del siglo XVII, a ser propiedad de la casa de Sarzedas y adquiere entonces su aspecto señorial por acción del nuevo propietario, D. Luís Lobo da Silveira, $2^{\circ}$ conde de Sarzedas.

D. Luís Lobo de la Silveira (1640-1706), hijo de los primeros condes de Sarzedas -D. Rodrigo Lobo da Silveira (m. 1656) y D. Maria Antónia de Vasconcelos (de la casa de los condes de

\footnotetext{
${ }^{4}$ Fernando Portugal, Alfredo de Matos, Lisboa en 1758. Memórias Paroquiais de Lisboa, Lisboa, Câmara Municipal de Lisboa, 1974, p. 263.

5 Augusto Soares de Azevedo Barbosa Pinho Leal, Portugal Antigo e Moderno, Vol. VI, Lisboa, Livraria Editora de Matos Moreira \& Cia., 1875, p. 425; cf. también Ignacio Vilhena Barbosa, "Fragmentos de um Roteiro de Lisboa (Inédito)", in Archivo Pittoresco, Vol. VI, Lisboa, Castro \& Irmão, 1863, pp. 81-82.

${ }^{6}$ Santos Farinha, O Palácio de Palhavan. Subsidios para a História de Lisboa Antiga, Lisboa, Parceria António Maria Pereira, 1923, p. 10.

7 Cf. Nicolas Franco, "O Palácio de Palhavã”, in Revista Municipal, Lisboa, Ano 1, Nº 2, 1939, pp. 49 - 51 y Pedro Ortiz Armengol, El Palacio de Palhavã, Lisboa, Serviços Culturais de la Embaixada de Espanha en Lisboa, 1971; cf. también A. Ayres de Carvalho, Documentário Artístico do Primeiro Quartel de Setecentos Exarado nas Notas de los Tabeliães de Lisboa, (separata de Bracara Augusta, Vol. XXVII, Fasc. 63/75), Braga, 1974, p. 5.

8 Cf. Ana Cristina Leite, O Jardim em Portugal nos Sécs. XVII e XVIII, (Tesis de Mestrado presentada a la Facultad de Ciencias Sociales y Humanas de la Universidad Nova de Lisboa), Lisboa, 1988, p. 45 (texto fotocopiado), Júlio Gil, Os Mais Belos Palácios de Portugal, Lisboa, Editorial Verbo, 1992, pp. 211-213 y Ana Cristina Leite, Alegorias do Mundo: a Arte dos Jardins, in Paulo Pereira, (dir. de), História da Arte Portuguesa, Vol. 3, Lisboa, Círculo de Leitores, 1995, p. 211.

${ }^{9}$ Cf. Norberto de Araújo, Inventário de Lisboa, Fasc. VI, Lisboa, Câmara Municipal de Lisboa, s.d., p. 11.
} 
Liñares) — y casado, desde 1654, con D. Mariana da Silva e Lencastre (hija y heredera del Regidor de las Justicias João Gomes da Silva), desempeñó a lo largo de su vida muchos cargos en el aparato del Estado en la regencia y reinado de D. Pedro II, principalmente los de gobernador del Algarve, veedor de Hacienda (por carta regia del 12 de Agosto de 1701), miembro del consejo de Estado (a partir del 11 de Abril de 1704) y miembro del consejo de Guerra ${ }^{10}$.

La proximidad a la casa real por parte del $2^{\circ}$ conde de Sarzedas se constata no solamente por los cargos para cuyo desempeño es escogido por el monarca portugués sino igualmente por el hecho de ser su propiedad de Palhavã — que se había ocupado en engrandecer y ennoblecer- la elegida para la convalecencia de la reina D. Maria Francisca Isabel de Saboya. Efectivamente, la primera esposa de D. Pedro II se instala en la finca de los condes de Sarzedas buscando mejorías que no obtiene y es precisamente en Palhavã que vendría a fallecer, el 27 de diciembre de 1683, después de una permanencia de aproximadamente un año en el palacio ${ }^{11}$.

Igualmente emprendedor y empeñado en la realización de obras en la propiedad de Palhavã es el hijo y heredero del $2^{\circ}$ conde de Sarzedas, D. Rodrigo da Silveira Silva e Teles, $3^{\circ}$ conde del título.

D. Rodrigo (1663-1735), que fue diputado de la Junta de los Tres Estados y capitán de la Guardia Real, acompañó, en el desempeño de este último cargo, a D. Pedro II durante la campaña de la Beira en la Guerra de Sucesión de España (1704) y participó como voluntario en las conquistas de Valença y Albuquerque, al año siguiente.

El $3^{\circ}$ conde de Sarzedas se casó dos veces, la primera en 1689, con D. Inácia de Noronha (hija de los condes de los Arcos, m. 1700) y la segunda en 1707, con D. Bernarda Josefa de Távora (hija de los marqueses de Távora, m. 1735) ${ }^{12}$.

D. Rodrigo se empeña, de hecho, en la realización de restauraciones en la finca de Palhavã, siendo por ejemplo responsable de la edificación del monumental portal noble de acceso al patio, que aun hoy se puede observar (aunque ya no tiene las armas de los Sarzedas) ${ }^{13}$.

Cualquiera de los dos condes podría, desde un punto de vista estrictamente cronológico, ser quien encargó la estatuaria italiana para la propiedad de Palhavã. La atribución de la autoría de (algunas) obras a Gianlorenzo Bernini situaría obligatoriamente el encargo en vida del $2^{\circ}$ conde. Sin embargo, una atribución al cavaliere por parte de autores del siglo XIX frecuentemente traduce solamente el deseo de acentuar la fama y la calidad de las obras y significa solamente el situar el origen, más o menos difuso, de tales obras en el contexto de la producción escultórica del barroco italiano. Así, no creemos que haya que aceptar una tal atribución, incluso porque, efectuando una aproximación a las obras supervivientes, sólo indirectamente podremos llegar a la producción berniniana, como a continuación veremos.

En cuanto a la formación cultural de estos titulares nada concreto nos es posible saber que nos permita aproximarnos a la construcción de un perfil capaz de explicar las motivaciones de una importación de obras de arte italiano. Ocupados en cargos político-administrativos o implicados

10 Cf. D. António Caetano de Sousa, História Genealógica da Casa Real Portuguesa, Tomo V, Lisboa, Regia Officina Sylviana, 1741-1752, p. 140 y A. E. Martins Zúquete, Nobreza de Portugal, Vol. III, Lisboa - Rio de Janeiro, Editorial Enciclopédia, s.d., pp. 362-363.

11 Cf. el instrumento de aprobación del testamento de la reina, realizado por el secretario de estado D. Fr. Manuel Pereira que se inicia "Em 21 de Novembro de 1683 no Lugar de Palhauãa na quinta em que assiste a Rainha Nossa Senhora (....).", Arquivo Nacional da Torre do Tombo (Lisboa), Gavetas, Gaveta XVI, Maço 2, Doc. 23, publ. por António da Silva Rego, (dir. de), As Gavetas de la Torre del Tombo, Vol. IV, Lisboa, Centro de Estudos Históricos Ultramarinos, 1967, pp. 235-243; cf. además Teresa Leonor M. Vale, D. Fr. Manuel Pereira Bispo e Secretário de Estado, Lisboa, Ed. Gleba, 1994 , pp. 33-34 y 67-68.

12 Cf. D. António Caetano de Sousa, op. cit., Tomo V, p. 140 y A. E. Martins Zúquete, op. cit., Vol. III, p. 363.

13 Cf. Santos Farinha, op. cit., pp. 28 - 29, Noberto de Araújo, op. cit., p. 11 y Pedro Ortiz Armengol, op. cit., p. 16; cf. también Hélder Carita, Oriente e Ocidente nos Interiores em Portugal, Porto, Livraria Civilização Editora, s.d., pp. 86-87; la piedra de armas que en la actualidad se observa sobre el portal data del siglo XIX y pertenece a la familia Mendonça. 
en campañas militares, poca disponibilidad se encontraría en la existencia de los $2^{\circ}$ y $3^{\circ}$ condes de Sarzedas para la realización de viajes, para los cuales no tendrían tal vez siquiera interés intelectual. De igual modo, sus intereses literarios permanecen desconocidos, al contrario de lo que ocurre con otros aristócratas coetáneos que atrás merecieron nuestra atención, y de que los $2^{\circ}$ y $3^{\circ}$ condes de la Ericeira son ejemplo. Curiosamente estos Sarzedas tienen relación con la casa de los Meneses, condes de la Ericeira, que van a convertirse incluso en sus herederos, a través del matrimonio, celebrado en el año de 1688 , entre una hija del $2^{\circ}$ conde (D. Joana Madalena de Noronha) y el $4^{\circ}$ conde de Ericeira, D. Francisco Xavier de Meneses (1673-1743) ${ }^{14}$.

\section{Las obras de escultura supervivientes}

Para una eficaz comprensión del conjunto de piezas de escultura supervivientes es importante llevar a cabo un reconocimiento, aunque muy sumario, de los principales acontecimientos relativos a la propiedad de Palhavã posteriores a la desaparición del último conde de Sarzedas que ha merecido nuestra atención, D. Rodrigo de la Silveira Silva e Teles, $3^{\circ}$ del título.

Se sigue una breve síntesis cronológica relativa a la finca de Palhavã que se perfila, en cierta medida, como explicativa de las vicisitudes de las cuales resulta superviviente el conjunto escultórico que en la actualidad nos es posible observar:

1735 fallecimiento del $3^{\circ}$ conde de Sarzedas sin descendiente varón, por lo que el título y las propiedades pasan a su hija, D. Teresa Marcelina de Noronha Lobo da Silveira, casada con D. António Luís de Távora (hijo de los condes de Alvor), su tío.

1747 fallecimiento de la $4^{a}$ condesa de Sarzedas sin descendencia directa, pasando la propiedad de Palhavã a la casa de los condes de la Ericeira y marqueses del Louriçal, en la persona de D. Francisco Xavier Rafael de Meneses ( $6^{\circ}$ conde y $2^{\circ}$ marqués); durante parte de los reinados de D. João V y de D. José I el palacio funciona como residencia de los denominados "Meninos de Palhavã" (hijos naturales del Magnánimo), conociendo diferentes obras y mejoras.

1760-77 el palacio permanece abandonado durante el exilio de los "Meninos de Palhavã", determinado por el marqués de Pombal.

1787 por la extinción de la casa de los condes de Ericeira y marqueses del Louriçal la propiedad pasa a manos de los condes de Lumiares.

1807-08 la propiedad sufre distintos daños durante las invasiones francesas.

1833 daños infligidos por el hecho de la finca de Palhavã haber quedado en la línea de fuego entre las tropas liberales y absolutistas durante el cerco de Lisboa.

1861 el $6^{\circ}$ y último conde de Lumiares, D. José Manuel da Cunha e Faro Meneses Portugal da Silveira (1836-1902), vende el palacio de Palhavã — llevando no obstante a su residencia en el centro de Lisboa algunas de las estatuas de menores dimensiones ${ }^{15}-\mathrm{al}^{\circ}{ }^{\circ}$ conde de Azambuja, D. Augusto Pedro de Mendoça (1835-1914, hijo del $1^{\circ}$ duque de Loulé y de la infanta D. Ana de Jesus Maria), que de inmediato emprende grandes restauraciones y mejoras en la propiedad.

1914 el fallecimiento del $3^{\circ}$ conde de Azambuja y las inherentes divisiones entre herederos conducen la finca de Palhavã a ser subastada, siendo adquirida por un comerciante de

\footnotetext{
14 Cf. A. E. Martins Zúquete, op. cit., Vol. II, p. 562.

15 Cf. Augusto Soares de Azevedo Barbosa Pinho Leal, op. cit., Vol. VI, p. 425.
} 


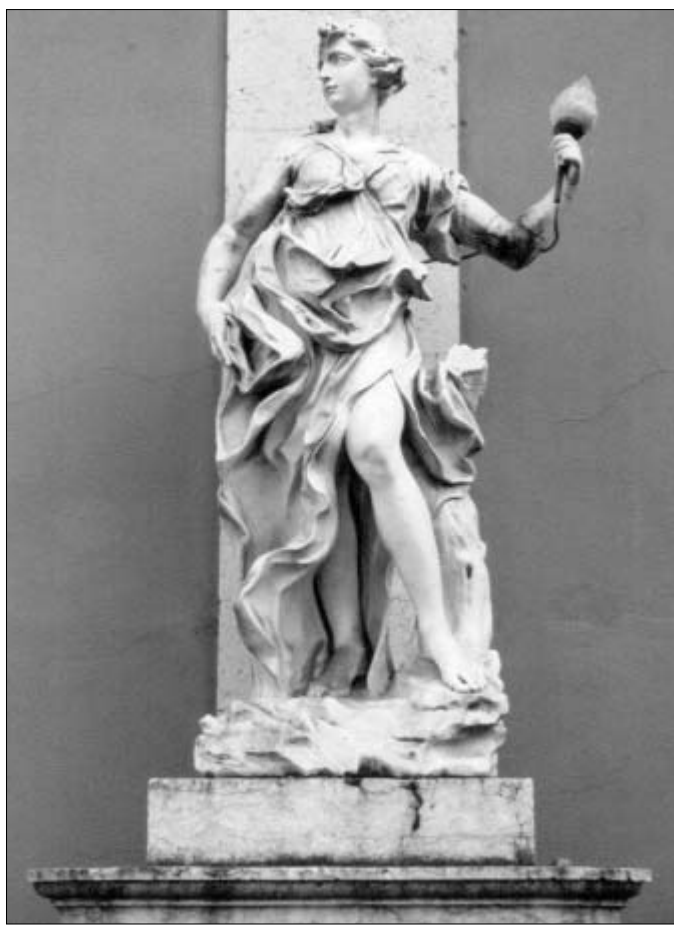

Fig. 5. Estatua genovesa.

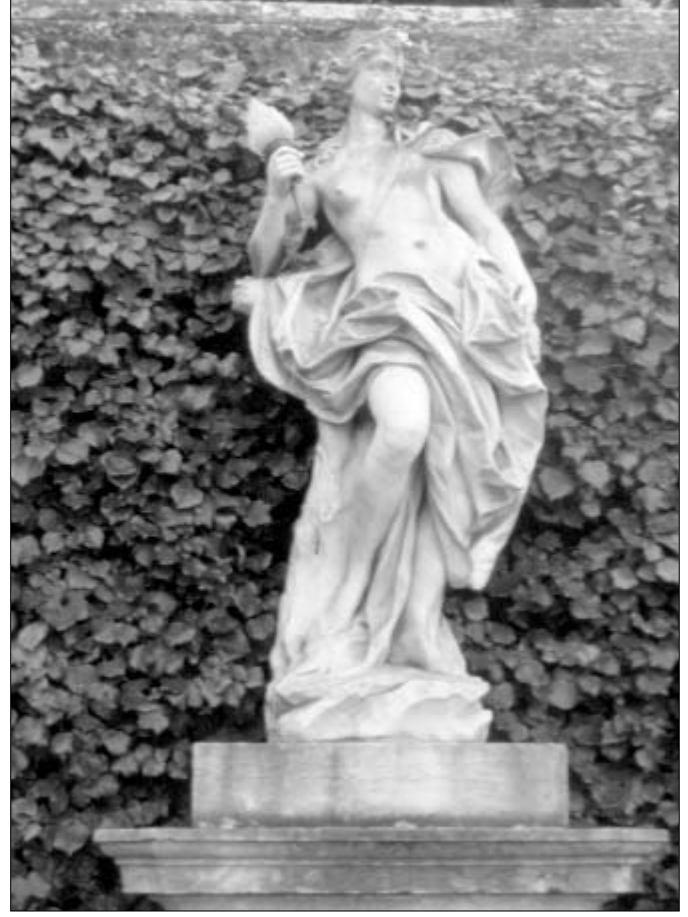

Fig. 6. Estatua genovesa.

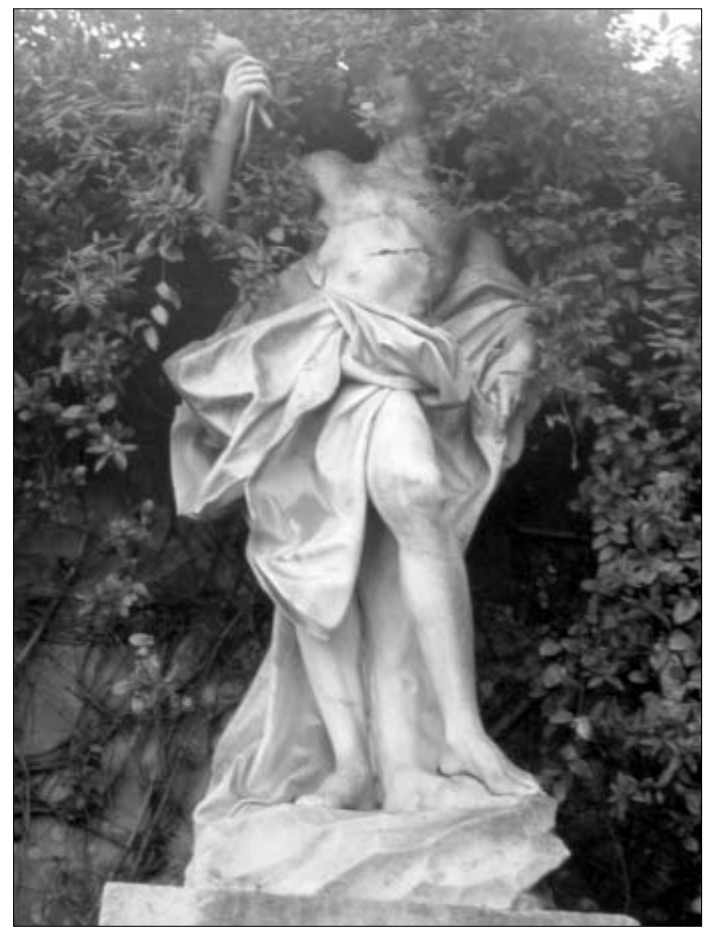

Fig. 7. Estatua genovesa.

AEA, LXXIX, 314, ABRIL-JUNIO, 123-138, 2006, ISSN: 0004-0428 
la capital que, cuatro años más tarde la vende al gobierno de España que instala ahí su embajada16.

Como resultado de las vicisitudes sufridas por la propiedad, pueden hoy reconocerse como supervivencias de una primitiva componente escultórica, total o parcialmente importada, las siguientes obras:

- tres fuentes (siendo dos idénticas entre sí y una tercera de mayores dimensiones);

- una estatua figurando Hércules;

- cuatro estatuas de temática mitológica o alegórica.

\section{Las fuentes}

Las tres fuentes, íntegramente en mármol blanco, se encuentran en la actualidad dispuestas en línea (norte-sur) en el jardín que se extiende — con una cota superior relativamente al patio y al acceso principal - a lo largo del alzado naciente del palacio (Fig. 8).

Aproximadamente en el centro del extenso césped se observa la fuente principal (Fig. 9), de mayores dimensiones, constituida por un grupo escultórico central — cuatro tritones soplando conchas, soportando una plataforma intermedia con forma de concha, sobre la cual se eleva una figura femenina (probablemente Venus, siendo el tema de la fuente el nacimiento de esta diosa, ocurrido en el seno de las aguas o eventualmente aún una figuración alegórica de la Fortuna), sentada sobre dos delfines de colas entrelazadas, y dos putti montando peces menores- y pilón polilobado, ornamentado en la cara externa con motivos geométricos y carátulas.

Las fuentes de los extremos, de menores dimensiones, se presentan estructuralmente idénticas a la fuente principal y entre ellas. En el centro de los pilones de planta octogonal se elevan elementos de soporte (ornamentados con carátulas, guirnaldas y festones) con plataforma intermedia, sobre la cual se reconoce un plinto con putti coronado por una figura femenina en pie.

Sobre un eventual origen de estas fuentes en el contexto de la producción escultórica del seicento italiano se imponen algunas consideraciones.

Casi como punto previo es necesario mencionar el hecho de que el grupo de los tritones de la fuente central — por las características del mármol (diferente tonalidad y granulosidad), por el tratamiento de la superficie escultórica y además por la rigidez de la representación de ciertos componentes (las manos y la forma como se apoyan sobre los muslos, por ejemplo) — se perfila de origen diverso y probablemente posterior al resto de la obra.

En lo que atañe a la figura femenina (Venus o Fortuna) de la misma fuente (Fig. 10), las opciones compositivas (en S) y plásticas que presidieron su realización pueden, efectivamente, encuadrarse en el panorama del barroco italiano. Hay que señalar el dinamismo de los miembros inferiores, ampliado por los brazos, el izquierdo agarrando la cola de uno de los delfines y el derecho levantando un ropaje que, sugiriendo una vela hinchada por el viento, define en el aire una curva en movimiento y se constituye como un audaz ejercicio de destaque de parte de la masa. Esta figura femenina se revela como el elemento escultóricamente más notable y más probablemente italiano (o italianizante) del conjunto de las fuentes del jardín del palacio de Palhavã.

Las fuentes menores denotan, de un modo general, la realización de intervenciones y adaptaciones: igualmente las bases se nos perfilan posteriores y la conexión, entre las peanas con putti

16 Para la síntesis cronológica hemos recurrido esencialmente a las siguientes obras: Santos Farinha, op. cit., Noberto de Araújo, op. cit., p. 11, Júlio Gil, op. cit., pp. 210-217 y Pedro Ortiz Armengol, op. cit. 
y la estatua femenina que sostienen, se presenta bastante deficiente. Confirmando la existencia de intervenciones y/o adaptaciones, muy probablemente en la secuencia de accidentes responsables de los daños en las obras, pueden observarse en las figuras femeninas fracturas al nivel del cuello y mutilaciones (manos derechas desaparecidas en ambas estatuas). Aunque en estas figuras puede constatarse un tratamiento sumario de la cara posterior (más evidente en la estatua de la fuente situada al norte), el cual evidencia una hipotética colocación primitiva a lo largo de un muro (de jardín o de construcción), el cual, una vez más, confirma la idea de adaptación.

\section{El Hércules}

La estatua de Hércules (Fig. 1) se encuentra colocada sobre una pequeña plataforma circular con césped, implantada en el centro del patio de acceso. Se trata de una figuración del famoso héroe de la Antigüedad característicamente barroca, una vez que ha sido intención del escultor representar a Hércules en acción, en un momento de uno de sus trabajos: la lucha con la hidra de las siete cabezas. La bestia se encuentra sujetada entre las piernas y por la mano izquierda de Hércules, mientras la derecha empuña enérgicamente una maza. La piel de león que la figura exhibe sobre la cabeza y el torso remite a la realización de otro de sus trabajos ${ }^{17}$.

Compositiva y plásticamente bastante elaborada, esta figuración de Hércules podría tener origen en el contexto de la producción escultórica del seicento italiano. De hecho, puede reconocerse un conjunto de características afines a las obras de escultura barroca italiana del siglo XVII en esta estatua de Palhavã, principalmente:

- el dinamismo y la evidente preocupación por la representación del movimiento, de un determinado momento del desarrollo de una acción (traducidos claramente en la gestualidad de Hércules y en la pluridireccionalidad de las cabezas de la hidra);

- la proporción y corrección anatómica, a pesar del hiperdesarrollo de la masa muscular que caracteriza frecuentemente las representaciones de Hércules;

- la clara diferenciación de la superficie escultórica según los materiales que representa, creando el escultor múltiples texturas (correspondiendo a la piel, a los pelos, al vello, a la roca, etc.), con preocupaciones de verosimilitud y no optando por simples convenciones de representación escultórica.

Se trata de una escultura de bulto pleno, permitiendo al observador distintos puntos de vista, a su alrededor (Figs. 2 y 3 ).

Este hecho permite pensar en una localización inicial muy probablemente en el centro de una fuente. De las bocas abiertas de la hidra - entrelazada en las piernas y en el torso de Hércules- corría agua lanzada en distintas direcciones. Este hecho justificaría las palabras del Pe. António Carvalho de la Costa que, en el inicio del siglo XVIII, puede haber visto la obra: “(...) tres jardins, o mayor cõ tres fontes de pedra de excellente fabrico, que vierão de Italia com hum Hercules de pedra fina [de] marmore, lançando agua por muytas partes de seu corpo (...).' (subrayado nuestro) ${ }^{18}$.

\footnotetext{
17 Sobre Hércules cf. por ejemplo: Pierre Grimal, Dicionário da Mitologia Grega e Romana, $4^{\mathrm{a}}$ ed., Lisboa, Difel, 2004, pp. 222-223 ( $1^{\text {a }}$ ed. 1951) y Jean Chevalier, Alain Gheebrandt, Dictionnaire des Symboles, $14^{\text {a }}$ edição, Paris, Robert Laffont / Jupiter, 1992, pp. 497-498 ( $1^{\text {a }}$ ed. 1982).

18 Pe. António Carvalho da Costa, op. cit., Vol. III, p. 340.
} 
Más arriba hemos tenido ocasión de mencionar como el embajador D. Luís de Sousa se constituyó como un significativo agente importador de obras de arte para su propia colección — consta que, en Enero de 1681, fecha cercana a su regreso al reino (ocurrido en 1682), el prelado embajador tenía al menos quince cajas con objetos en el puerto de Livorno, listas para ser llevadas a Lisboa ${ }^{19}$ y también para terceros- es el caso de la fuente para el conde de Ericeira. Ahora bien, D. Luís de Sousa era indiscutiblemente persona del círculo de los condes de Sarzedas (sobre todo del $2^{\circ}$ conde, por afinidades generacionales, ya que este era solamente tres años más joven) y tal vez no solamente por compartir los mismos ambientes cortesanos o integrar órganos del aparato del Estado, una vez que el 17 de septiembre de 1675, cuando D. Luís embarca en el Cais da Pedra con destino a Roma con el fin de iniciar su embajada, los condes de Sarzedas hacen cuestión de estar presentes y subir a bordo de la nao que llevará el obispo diplomático al puerto de Génova ${ }^{20}$.

Por consiguiente, la presencia en los jardines de Palhavã de la estatua de Hércules - también ella protagonista de una fuente, como aquella de Neptuno, de los Ericeira- podrá haber sido resultado de la existencia de esta relación entre los condes de Sarzedas y D. Luís de Sousa, solicitando la acción de este último en Roma.

\section{Las piezas genovesas}

Colocadas sobre grandes plintos de sección cuadrada, las cuatro estatuas —en ronde bosse, realizadas en mármol blanco, en una escala un poco superior a 1/1 - se disponen a lo largo de los muros que delimitan al sur (dos) y al este (dos) el patio de acceso al palacio de Palhavã $\tilde{a}^{21}$.

Se trata de un conjunto compuesto por dos figuras femeninas (Fig. 5 y 6) y dos figuras masculinas (Fig. 4 y 7) probablemente de carácter mitológico o alegórico pero cuya identificación se manifiesta hoy imposible, una vez que fueron mutiladas para servir de iluminadores (todas las estatuas tienen un brazo sustituido para que en la mano puedan sujetar un cirio iluminante).

Presentando opciones compositivas y plásticas profundamente barrocas, las cuatro estatuas de que nos ocupamos son de gran calidad escultórica y de evidente origen en el contexto de la escultura del seicento italiano.

Este origen italiano se traduce principalmente en los siguientes aspectos:

- opción compositiva por la figura serpentinata en todas las estatuas, siempre obtenida a través de la colocación de los puntos de apoyo en planos diferentes, para lo que contribuye la concepción naturalista de las bases, poseedoras de un carácter interpenetrante o participante relativamente a la estatua, como es característico de la escultura barroca italiana;

\footnotetext{
19 Referencia hecha en una carta de D. Luís de Sousa a D. Luís de Meneses, $3^{\circ}$ conde de Ericeira, escrita desde Roma el 18 de enero de 1681: A.N.T.T., Manuscritos da Livraria, No 442: D. Luís de Sousa, Cartas Políticas, fls. 135-136v. publ. por Teresa Leonor M. Vale, A Importação de Escultura Italiana en el Contexto das relações Artístico-Culturais entre Portugal e Itália no Século XVII, (...), Vol. II, Documento 16.

20 Biblioteca Nacional (Lisboa), Sección de Reservados, Fundo Geral, Cod. 408, Diario de la iornada que fes el Illustrissimo Señor Bispo de Lamego Dom Luis de Souza Embaixador Extraordinario del Princepe Dom Pedro, la Santidade del Pappa Clemente Decimo en la era de 1675 annos., fl. 1 v. (manuscrito cuya edición estamos preparando).

21 Insertadas en nichos abiertos en los muros este y oeste de la galería que alberga la escalera de acceso a la puerta principal del palacio se encuentran dos estatuas que nos parecen ser de realización tal vez posterior y teniendo las otras cuatro como modelo. Son verdaderos porta-velas (mientras en las otras se registró una adaptación), se presentan menos dinámicas compositiva y plásticamente, exhibiendo un tratamiento completamente distinto de la superficie escultórica y una distinta concepción de las bases.
} 


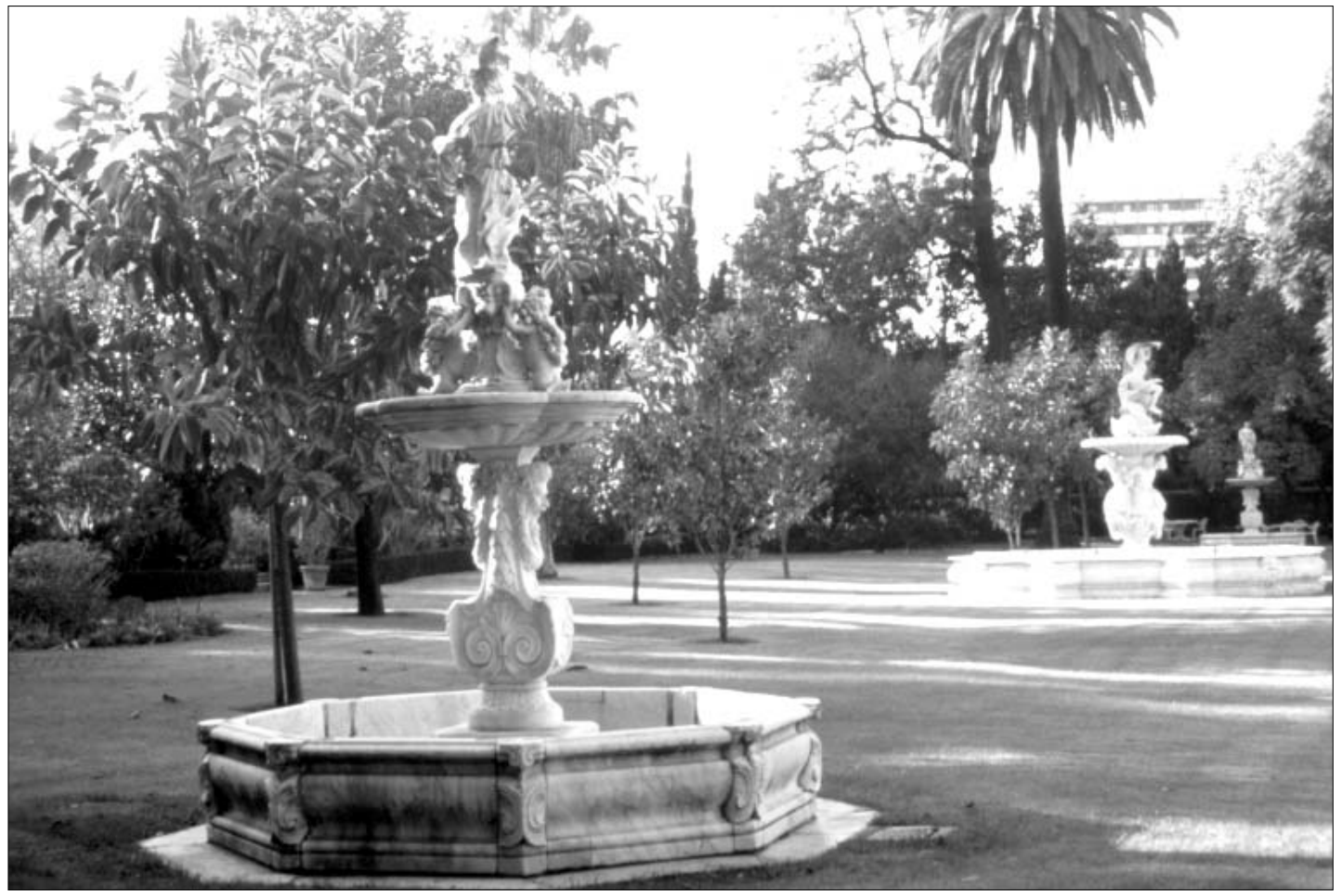

Fig. 8. Vista del jardín superior del palacio de la embajada de España en Lisboa.

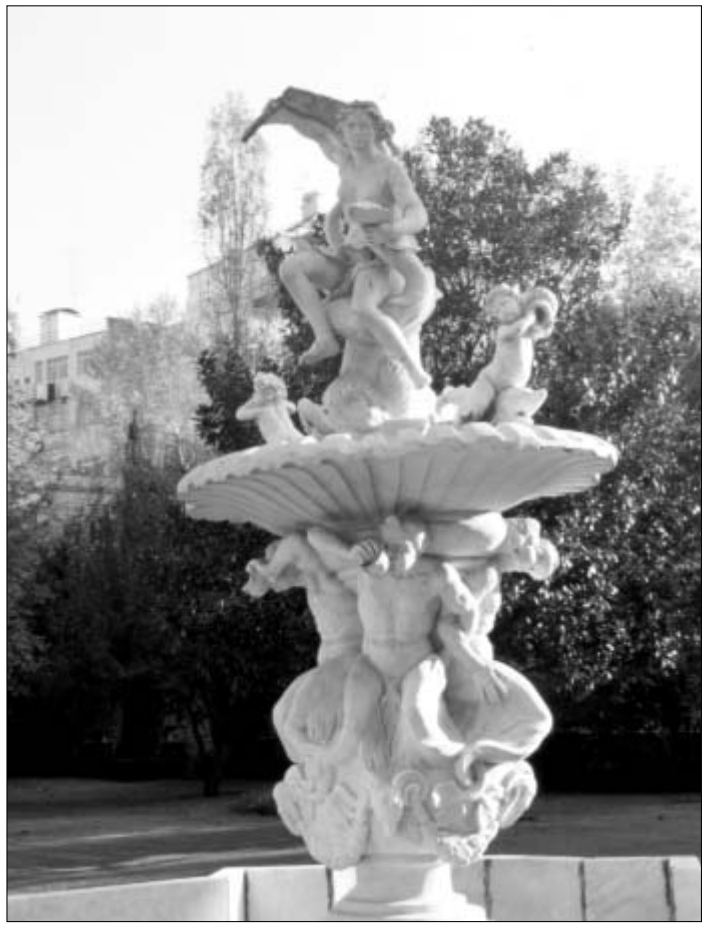

Fig. 9. Fuente central.

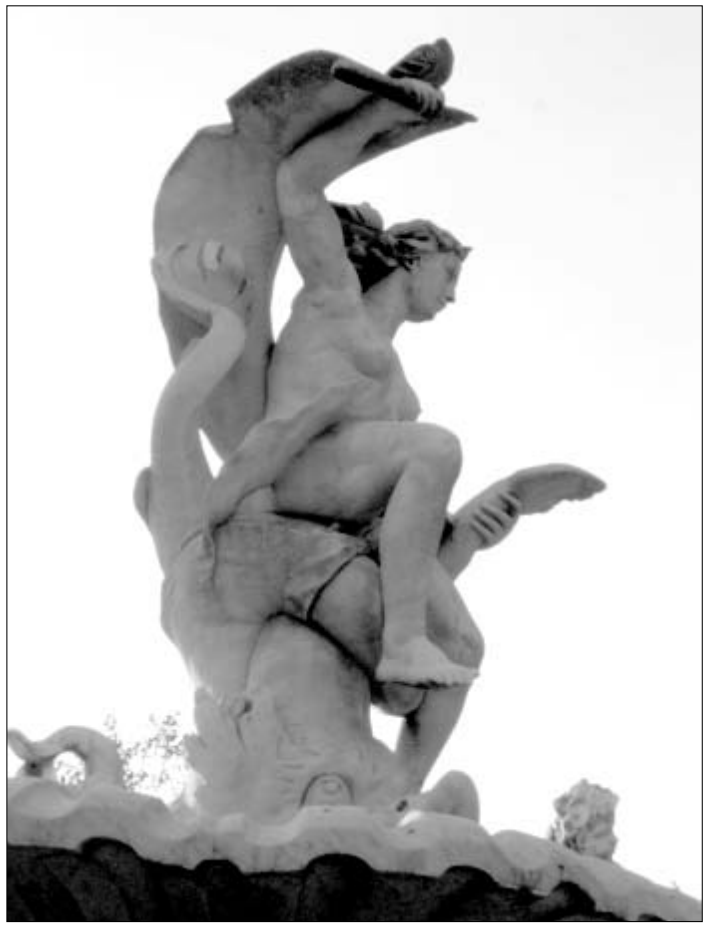

Fig. 10. Fuente central - detalle de la figura femenina.

AEA, LXXIX, 314, ABRIL-JUNIO, 123-138, 2006, ISSN: 0004-0428 
- tratamiento muy elaborado de los vestuarios, transformados en masas de gran dinamismo, desarrollados en múltiples superficies, a través de muchas líneas de quiebra, con gran verosimilitud;

- traducción de los distintos materiales representados por un tratamiento diferenciado de la superficie escultórica.

Italianas, sin margen de dudas, por el análisis compositivo y plástico, la confirmación del carácter importado de estas cuatro estatuas del patio del palacio de Palhavã surge por la presencia de la firma del escultor en dos de las obras: BER NUS SCHIAFFINUS SCULP.

La firma revela por consiguiente el autor: Bernardo Schiaffino (1678-1725), escultor genovés discípulo de Domenico Parodi (1672-1742, hijo del escultor Giacomo Filippo Parodi) y así integrado en la producción escultórica genovesa que se ha caracterizado, en el siglo XVII, por una significativa influencia berniniana a través de la figura dominante de Giacomo Filippo Parodi (1630-1702), que se trasladó a Roma y trabajó en la esfera del gran maestro del barroco romano.

No obstante, el interés por la escultura barroca por parte de Génova ha sido desde temprano alimentado por la presencia de obras y de artistas con origen extraño a la ciudad. Entre las obras se destaca la presencia del seicento romano por vía algardiana a través del componente escultórico de la capilla Franzoni de la iglesia de S. Carlo, realizada por Alessandro Algardi (1598-1654), la cual se revela de la mayor importancia por el significativo impacto que conoció en el momento de su conclusión 22 .

Entre los artistas, extraños a la ciudad pero habiendo asimilado en Roma las más recientes tendencias escultóricas, merece particular mención el francés Pierre Puget (1620-1694) que, después de dos permanencias en Roma - donde contacta con el atelier de Algardi (y concretamente con su discípulo Ercole Ferrata ${ }^{23}$ y trabaja en estrecha colaboración con el arquitecto Pietro de la Cortona-, pasa por Mantua y se establece en Génova en 1660, permaneciendo en esa ciudad hasta $1668^{24}$.

Activo en Génova desde 1660, es posible que Puget estuviera ya completamente establecido en 1633, cuando hace que se le una en aquella ciudad de Ligúria la familia y además dos discípulos: Christophe Veyrier (1637-1689) y Honoré Pellé (164-1718), los cuales acabarán igualmente desarrollando actividad significativa en el contexto de la producción escultórica de Génova.

En Génova, Puget desarrolla la fase más rica y elaborada de su obra escultórica, atendiendo múltiples encargos de estatuas para iglesias de la ciudad (realizando incluso proyectos para la globalidad del altar que recibiría la imagen), pero también de piezas variadas para influyentes familias genovesas 25 , entre las cuales reconocemos los Lomellini y los Carrega, estos últimos bien

22 Cf. Rudolf Wittkower, Art and Architecture in Italy: 1600-1750, $3^{\mathrm{a}}$ ed., (col. The Penguin History of Art), Londres, Penguin Books, 1973, p. 297 (1 ${ }^{\text {a }}$ ed. 1958).

${ }^{23}$ Cf. Klaus Herding, Puget Sculpteur, in AAVV, Pierre Puget. Peintre, Sculpteur, Architecte 1620 - 1694, Paris, Musées de Marseille-Réunion des Musées Nationaux, 1994, p. 90.

${ }^{24}$ Cf. Rudolf Wittkower, op. cit., p. 297, Simone Hoog, Pierre Puget, in Jean-Philippe Breuille, (dir. de), Dictionnaire de la Sculpture, Paris, Larousse, 1992, pp. 348-440 y sobre todo los textos de distintos autores en AAVV, Pierre Puget. Peintre, Sculpteur, Architecte 1620-1694, (...), pp. 88-169 y 254-377 y además AA.VV., Pierre Puget (Marsiglia 1620-1694) Un Artista Francese e la Cultura Barocca la Genova, Milán, Electa, 1995.

25 En el contexto de la obra escultórica de Puget destacamos a continuación las piezas realizadas durante su estancia en Roma y Génova (se encuentra indicada la técnica siempre que no se trate de estatuaria de bulto y el material siempre que no sea mármol): Busto de Filósofo, 1662, The Museum of Art, Cleveland; Hércules Gaulês, 1663, Museo del Louvre, Paris; altar-mayor, 1663-1670, iglesia de S. Ciro, Génova; Asunción de la Virgen (relieve), 1664, Albergo dei Poveri, Génova; Asunción de la Virgen (relieve), 1665, Staatliche Museum, Berlim; Bienaventurado Alessandro Sauli, 1668 - 1669, iglesia de Santa Maria Assunta, Carignano; S. Sebastián, 1668 - 1669, iglesia de Santa Maria Assunta, Carignano; Inmaculada Concepción, 1669, iglesia de S. Filipe de Néri, Génova; Virgen con el Niño (Virgem Carrega), c. 1680, Museo de Sant'Agostino, Génova. 
representados en la comunidad italiana residente en Lisboa a través de Francisco André Carrega (m. 1676), quién compartía con los Ghersi y con Nicolau Micon una posición dominante en el seno de la comunidad. Para los parientes de Francisco André Carrega residentes en Génova, Puget realizó un conjunto de doce bustos de emperadores romanos (uno de los cuales fue esculpido por Parodi) y la conocida Vírgen Carrega ${ }^{26}$.

Como formuló muy bien Rudolf Wittkower a propósito de la trayectoria de Puget: "He had absorbed Bernini's and Cortona's style in Rome, and his works at Genoa with their Berninesque vigour and fire of expression had la decisive influence on the formation of la school of sculptors in that city." 27.

Filippo Parodi, el primer gran escultor barroco nacido en Génova, según Wittkower ${ }^{28}$, obtuvo su formación artística decisiva en Roma, en el amplio atelier de Gianlorenzo Bernini.

La permanencia romana de Parodi — de 1655 a 1661 — le habrá permitido no sólo observar sino también participar en la intensa producción escultórica que de forma imparable rellenaba iglesias y palacios, poblaba plazas y animaba jardines.

Integrado en el amplio abanico de discípulos y colaboradores de Bernini, Parodi parece haber estado muy concretamente conectado a Ercole Ferrata (1610/14-1686) y a su taller ${ }^{29}$.

$\mathrm{Su}$ regreso a Génova y su encuentro con Puget en su ciudad de origen permitieron dar un significativo impulso en la introducción y divulgación del barroco romano en Liguria.

Sus obras, las de las décadas de 60 y 70 sobre todo, se integran perfectamente en el seicento romano, revelando afinidades con los estilos de Antonio Raggi (1624-1686) y Melchiorre Caffà (1635/38-1667), según Wittkower ${ }^{30}$, sin duda los escultores que más lo marcaron (por su creatividad y osadía) a pesar de que Parodi estuviera particularmente asociado al atelier de Ferrata, también artista dotado de notables cualidades, las cuales le aseguraron la posición preponderante de que gozó después de desaparecido Bernini en el panorama de la producción escultórica romana.

De esta primera parte de su obra escultórica son ejemplo el Éxtasis de Santa Marta, que realizó para la iglesia genovesa de la misma advocación, y el S. Juan Bautista, que esculpió para la iglesia de Santa Maria Assunta de Carignano.

En un segundo momento - referente a su período véneto, después de 1683 y después de la actividad desarrollada preferentemente en Génova y sus dos viajes a Roma - se registra una evolución por la que se asiste a una delicada articulación entre las enseñanzas berninianas recogidas en Roma y un estilo proto-rococó, que se revela como nueva tendencia y se reconoce en las obras de otros escultores activos en Roma en los últimos años del siglo XVII y primeros años de la centuria siguiente ${ }^{31}$.

26 Actualmente en el Museu de Sant'Agostino de Génova; cf. Klaus Herding, op. cit., p. 91.

27 Rudolf Wittkower, op. cit., p. 297; cf. también Geneviève Bresc-Bautier, Pratiques d'Atelier de Pierre Puget, in AAVV, Pierre Puget. Peintre, Sculpteur, Architecte 1620 - 1694, (...), pp. 332-337.

28 Cf. Rudolf Wittkower, op. cit., p. 297.

29 Sobre Filippo Parodi cf. concretamente Gaude, Padua Felix! Sulle Ultime Orme del Santo di Padova nella Luce della Storia y dell'Arte, Padua, Libreria Editrice del Messaggero di S. Antonio, 1931, pp. 117-118, P. Rotondi Briasco, Filippo Parodi, Génova, 1962, Camillo Semenzato, Scultori Veneti del Seicento y del Settecento, Veneza, Alfieri, 1966 , p. 22, Rudolf Wittkower, op. cit., p. 297, Carlos Moura, Giacomo Filippo Parodi, in José Fernandes Pereira, (dir. de), Dicionário de Arte Barroca em Portugal, Lisboa, Editorial Presença, 1990, p. 344, Dominique Vergnon, Filippo Parodi, in Jean-Philippe Breuille, (dir. de), op. cit., pp. 410-411, Piero Boccaro, "Novità su Gregorio di Ferrari y Filippo Parodi. I Progetti per la Tomba del Doge Francesco Morosini y Alcuni Inediti”, in Bollettino dei Musei Civici Genovesi, Ano XV, No 43-44-45, Jan.-Dez. 1993, pp. 39-52, Lauro Magnani, Ezia Gavazza, Giovanna Rotondi Terminiello, Puget la la Gênes, in AAVV, Pierre Puget. Peintre, Sculpteur, Architecte 1620-1694, (...), pp. 254-259, Ezia Gavazza, "Puget et gli Artisti Genovesi: l'Incontro tra due Culture" in AAVV, Pierre Puget (Marsiglia 1620-1694) Un Artisa Francese y la Cultura Barocca la Genova, (...), pp. 82-98 y Maurizio Fagiolo Dell'arco, Baroque, in AAVV, Sculpture, Vol. III, Colónia, B. Taschen, 1996, p. 178.

30 Cf. Rudolf Wittkower, op. cit., p. 297.

31 Idem. 
De la segunda fase de la obra escultórica de Filippo Parodi es buen ejemplo el monumento fúnebre erigido al obispo Francesco Morosini en la iglesia de S. Nicolás Tolentino de Venecia y el conjunto escultórico de la capilla del Tesoro de la basílica de San Antonio de Padua ${ }^{32}$.

La importancia de Filippo Parodi se prolongó más allá de su vida y entre sus discípulos reconocemos nombres que forzosamente reencontramos cuando nos ocupamos de la escultura del settecento.

Es a través de la actividad de estos discípulos de Parodi por la que la producción escultórica de Génova se mantiene floreciente — gracias a las exportaciones a través del importante puerto de la ciudad - durante la centuria siguiente. Entre tales discípulos merecen mención: Domenico Parodi (1672-1742), su hijo, escultor, pintor y arquitecto, activo sobre todo en Génova ${ }^{33}$; Giacomo Antonio Ponsonelli (1654-1735), que acompañó el maestro en sus visitas y trabajos en Venecia y en Padua ${ }^{34}$; Angelo De Rossi (1671-1715), que acompaña Parodi a Venecia en 1683 y se perfilará como un importante escultor en el contexto romano (a De Rossi será incluso confiada la ejecución de uno de los apóstoles de la nave de la basílica de S. Juan de Laterano, siendo el monumental apostolado lateranense uno de los más importantes encargos pontificios de la primera mitad del siglo XVIII romano) ${ }^{35}$; los hermanos Bernardo (1678-1725) y Francesco Maria Schiaffino (1689-1765), que trabajaron ambos para Portugal y de quién nos ocuparemos a continuación con mayor detalle.

Bernardo Schiaffino, escultor de la transición del seicento al settecento y autor de cuatro estatuas del jardín del palacio de Palhavã, es claramente heredero de esta tradición escultórica genovesa. Propietario de un atelier importante en el contexto genovés, Bernardo Schiaffino fue maestro de los escultores Francesco Maria Schiaffino — su hermano y heredero del taller, que realizó

32 Entre las obras de Filippo Parodi se cuentan las siguientes (indicamos la técnica siempre que no se trate de estatuaria de bulto y el material siempre que no sea pétreo): Éxtasis de Santa Marta, iglesia de Santa Marta, Génova; S. Juan Bautista, iglesia de Santa María Assunta, Carignano; monumento fúnebre del obispo Francesco Morosini, después 1678, iglesia de S. Nicolás Tolentino, Venecia; monumento fúnebre del doge Francesco Morosini, iglesia de S. Esteban, Venecia; componente escultórica de la capilla del Tesoro, 1678-1702, basílica de S. Antonio, Padua (aunque se trate de una obra llevada a cabo por todo un atelier, Parodi habrá ejecutado personalmente algunas de las estatuas, concretamente las de Santo Antonio, S. Francisco y S. Buenaventura); monumento fúnebre de Orazio Secco, 1686, basílica de San Antonio, Padua, S. Pedro y S. Paulo, 1687, iglesia de S. Giorgio Maggiore, Venecia; Deposición, 1685-1688, capilla de la Piedad, basílica de Santa Justina, Padua, Ecce Homo, iglesia de S. Francisco, Padua; Telamon, Palacio Brignoli - Durazzo, Génova, Flora y Baco (busto), Villa Pisani, Stra, púlpito (madera), catedral de Padua; ángeles con velas, basílica de San Antonio, Padua; Inmaculada Concepción, Conservatorio de los Brignolini, Génova; Inmaculada Concepción, iglesia de Santa Maria della Cella, Sampierdarena (Génova); Cristo atado a la Columna, Palacio Real, Génova; Jacinto, Vénus, Clytia, Adónis, Palacio Real, Génova; Inmaculada Concepción, iglesia de S. Luca, Génova; Cristo Muerto (madera policromada), iglesia de S. Lucas, Génova; Santo Obispo (terracota), Museo Grobet-Labadié, Marsella; El Verano (madera dorada), Villa Durazzo o Faraggiana, Albisola (Savona); Adónis y el Amor, col. privada, Génova; El Juicio de Páris (moldura en madera dorada), Palacio Spinola, Génova.

33 Cf. Rudolf Wittkower, op. cit., p. 298 y textos de Carlo Milano in Luca Leoncini, (dir. de), Da Tintoretto a Rubens. Capolavori della Collezione Durazzo, Milán-Génova, Skira-Genova Capitale Europea della Cultura 04, 2004, pp. 336-337; entre las obras de Domenico Parodi se cuentan concretamente los bustos de Giacomo Antonio y Marcello I Durazzo, marqueses de Gabiano, col. privada, Génova.

${ }^{34}$ Cf. Édouard Bénézit, Dictionnaire Critique et Documentaire des Peintres, Sculpteurs, Dessinateurs et Graveurs, Vol. VI, [Paris], Gründ, 1966, p. 758; entre las obras de Ponsonelli se cuentan (indicamos la técnica siempre que no se trate de estatuaria de bulto y el material siempre que no sea pétreo): busto del cardenal Stefano Durazzo, 1677, Casa Missione di S. Vincenzo de' Paoli, Génova; busto de Marcantonio Grillo, Abergo dei Poveri, Génova y el altar-mayor de la iglesia de Santa Maria delle Vigne, Génova.

35 Cf. Rudolf Wittkower, op. cit., p. 298 y también Vittorio Moschini, "Scultura Barocca in Roma dopo il Bernini”, in La Cultura, Vol. II, Fasc. 8, 15 Jun. 1923, p. 350, s.la. Angelo De' Rossi, in Giovanni Gentile, Calogero Tumminelli, (dir. de), Enciclopedia Italiana, Vol. XXX, Milán, Istituto G. Treccani, 1932 - 1952, p. 141 y Édouard Bénézit, op. cit., Vol. VII, p. 363.

AEA, LXXIX, 314, ABRIL-JUNIO, 123-138, 2006, ISSN: 0004-0428 
algunas obras para Portugal en el reinado de D. João V36_ y Francesco Queirolo (1704-1762), que vino a desarrollar su actividad preferentemente en Nápoles.

Las obras de Bernardo Schiaffino, que denotan —en la temática, composición y plasticidaduna estrecha conexión con la pintura genovesa coetánea, evidencian una elegancia formal (bien patente en las estatuas de la embajada de España) que influenció toda la producción escultórica genovesa subsiguiente ${ }^{37}$.

Más allá del valor artístico de estas cuatro estatuas de Palhavã, se revisten de particular importancia por revelar la importación de escultura italiana por un agente privado en el tránsito del siglo XVII al siglo XVIII o en los primeros años de esta última centuria, cuya primera mitad estaría profundamente marcada por una política de importaciones liderada (cf. dominada) por la corona, estéticamente muy italianizada en el reinado de D. João V. El importador de estas estatuas, seguramente el $3^{\circ}$ conde de Sarzedas, D. Rodrigo de la Silveira Silva y Teles, prosigue de esta forma, muy probablemente en el primer cuarto del siglo XVIII, una práctica a la que vinculamos distintas individualidades en la segunda mitad de la centuria anterior, la importación de obras de escultura italiana.

Igualmente importante es el hecho de que estas cuatro estatuas vengan a enriquecer el panorama de la escultura italiana importada por agentes portugueses en el barroco y además probar la existencia en Portugal - y concretamente en los jardines del palacio de la embajada de Españade obras del mayor de los hermanos Schiaffino, hecho hasta hoy desconocido por la historiografía del arte portugués y extranjero, que se limitaba a reconocer la presencia de obras de su hermano Francesco Maria.

Puede por consiguiente afirmarse que, a pesar de las vicisitudes sufridas, a pesar de la erosión causada por el tiempo y, en suma, por la propia historia, en los jardines de la Embajada de España de Lisboa, se puede apreciar aun hoy un notable conjunto de obras de escultura barroca italiana de los siglos XVII y XVIII.

\footnotetext{
36 Cf. Soprani-Ratti, Vite dei Pittori, Scultori ed Architetti Genovesi, Vol. II, Génova, 1769 pp. 259 y 279, Caterina Marcenaro, Schiaffino, in Giovanni Gentile, Calogero Tumminelli, (dir. de), Enciclopedia Italiana, Vol. XXX, (...), p. 77, Giuseppe Delogu, La Scultura Italiana del Seicento e del Settecento, Florença, Sansoni, 1932, p. 48, Valentino Martnelli, "Due Modelli di Camillo Rusconi Ritrovati”, in Commentari, Ano IV, № 3, Jul.-Set. 1953, pp. 231-241, Édouard Bénézit, op. cit., Vol. VII, p. 584, Rudolf Wittkower, op. cit., pp. 391, 392 y 400, Pier Paolo Quieto, D. João V de Portugal. A sua Influência na Arte Italiana do Século XVIII, Lisboa-Mafra, Elo, 1990, p. 82, Sophie Bajard, Francesco Maria Schiaffino, in Jean-Philippe Breuille, (dir. de), op. cit., p. 501, Jennifer Montagu, D. João V and Italian Sculpture, in AAVV, The Age of Baroque in Portugal, New Haven-Londres, Yale University Press, 1993,p. 84, Jennifer Montagu, João V e la Scultura Italiana, in Sandra Vasco Rocca, Gabriele Borghini, (dir. de), Giovanni V di Portogallo e la Cultura Romana del suo Tempo, Roma, Árgos Edizioni, 1995, p. 388 y Teresa Leonor M. Vale, A Escultura Italiana de Mafra, Lisboa, Livros Horizonte, 2002, pp. 74-75; entre sus obras cuentan: crucifijo monumental, c. 1735, basílica de Nuestra Señora y San Antonio, Mafra; estatuas de santos (12), 1739/40, iglesia de Santa Maria Assunta, Carignano; Santa Ana y la Virgen, iglesia de Santa Ana, Génova; S. Domingos, iglesia de Santa Maria del Castello, Génova; Virgen de la Misericordia, iglesia de S. Pancracio, Génova, Nacimiento de Cristo, Presentación del Niño en el Templo, El Niño entre los Doctores, iglesia de las Scuole Pie, Génova (relieves); Virtudes, Hospital Pammatone, Génova; busto de Eugénio Durazzo, col. privada, Génova; Rapto de Proserpina, Palacio Real, Génova; Virgen con el Niño, Capela del Palacio Ducal, Génova; Inmaculada Concepción, Palacio Dória-Lamba, Génova.

${ }^{37}$ Sobre Bernardo Schiaffino cf. Caterina Marcenaro, op. cit., Vol. XXX, p. 77, Édouard Bénézit, op. cit., Vol. VII, p. 584, Rudolf Wittkower, op. cit., p. 298 (1 $1^{\text {a }}$ ed. 1958), y Fausta Franchini Guelfi, "Bernardo Schiaffino", in AAVV y La scultura a Genova e in Liguria dal Seicento al Primo Novecento, Genova, Cassa di Risparmio di Genova e Imperia, 1989, p. 282, entre las obras de Bernardo Schiaffino tenemos: estatua del Doge Giovanni Francesco Brignole Sale, Palacio Rosso, Génova; Narciso, Palacio Balbi, Génova; Virgen con el Niño, iglesia de Santa Maria della Consolazione, Génova.
} 